Para enlazar con este artículo / To link to this article:

http://dx.doi.org/10.14198/fem.2018.32.07

Para citar este artículo / To cite this article:

Nieto Fernández, Enrique. «Éticas y estéticas para una reconexión. Estudios de caso para una práctica de diseño ecológica». En Feminismo/s, 32 (diciembre 2018): 181-203. Dosier monográfico: MAS-MES: Mujeres, Arquitectura y Sostenibilidad - Medioambiental, Económica y Social, coord. María-Elia Gutiérrez-Mozo, DOI: $10.14198 / \mathrm{fem} .2018 .32 .07$

\title{
ÉTICAS Y ESTÉTICAS PARA UNA RECONEXIÓN. ESTUDIOS DE CASO PARA UNA PRÁCTICA DE DISEÑO ECOLÓGICA
}

\author{
ETHICS AND AESTHETICS FOR A RECONNECTION. CASE- \\ STUDIES FOR AN ECOLOGIC DESIGN PRACTICE
}

\author{
Enrique NIETO FERNÁNDEZ \\ Universidad de Alicante \\ Enrique.nieto@ua.es \\ orcid.org/0000-0002-8513-7115
}

\section{Resumen}

Este trabajo reflexiona sobre la capacidad fundante de las prácticas en el ámbito del diseño y sitúa en ella una de las aspiraciones para perfeccionar el diseño ecológico. Arrancaremos de perspectivas próximas al pensamiento feminista como las de Haraway, Stengers o Barad, quienes nos alertan sobre la necesidad de relacionarnos más y mejor con otras entidades más allá de lo humano. También de la propuesta de Braidotti sobre la pertinencia de actuar desde éticas y políticas afirmativas. Propondremos como inspiración la ruptura producida en la cultura científica con el trabajo de las primeras primatólogas en los años 60 donde el afecto, los cuidados o la empatía irrumpen en el espectro de lo valioso y significativo. La pregunta a examen es la posibilidad de repensar la creatividad en la arquitectura desde los dominios más cálidos del estar juntos. Finalmente se propondrán dos estudios de caso recientes donde se reconoce la operatividad de los aportes teóricos en las prácticas arquitectónicas.

Palabras clave: afirmatividad, primatólogas, afectos, empatía, arquitectura (CC BY 4.0)

Feminismo/s 32, diciembre 2018, pp. 181-203 


\begin{abstract}
This work reflects on the founding capacity in the domains of design and locates in its presence one of the aspirations to improve the so-named ecological design. We will begin from proposals close to feminist theory as that of Haraway, Stengers and Barad, who alert us of the needing to relate more and better with other entities beyond the humans. Also, from Braidotti proposal on the need for ethics and affirmative politics. As an example, we will propose the rupture produced in the scientific culture with the first women primatologist appearance in the 1960s, where affection, care and empathy, burst into the scope of what is valuable and significant. The final question to test is the possibility of rethinking creativity in architecture from the warmer domains of being together. Finally, we will explore two recent case studies where the operativity of these theoretical contributions in architectural practices can be recognized.
\end{abstract}

Keywords: Affirmativity, primatologist, affections, empathy, architecture

\title{
1. PROYECTO MODERNO Y DESAFÍOS ECOLÓGICOS
}

Este trabajo arranca con una serie de preguntas que nos parecen pertinentes: ¿Pueden las prácticas arquitectónicas ayudarnos a redefinir el estatuto de lo humano, en un mundo marcado por la negatividad? ¿Podemos reconocer itinerarios éticos asociados a las prácticas mismas de la arquitectura, capaces de mejorar la relacionalidad de nuestras prácticas desde el trabajo con la subjetividad, la diferencia, los afectos o los cuidados?

Estas preguntas emergen desde una preocupación por la dimensión política de las prácticas arquitectónicas en un mundo caracterizado por un incremento de la vulnerabilidad y la negatividad, así como por la dificultad para producir imaginarios de futuro afirmativos que se despeguen de una dialéctica de oposición para anclarse en la producción de alternativas encarnadas y viables. Emergen también desde una preocupación creciente por el futuro de las prácticas arquitectónicas en un contexto occidental marcado por los debates en torno al cambio climático y la puesta en crisis de la razón ilustrada como modelo único de conocer y relacionarse con el mundo. En su conjunto, estas preguntas nos interrogan sobre la posibilidad de superación de las éticas kantianas en el ámbito del diseño arquitectónico, aquellas que durante tanto tiempo han privilegiado al hombre sobre el resto de entidades, sobre todos aquellos sujetos feminizados, racializados, naturalizados, enfermados,

Feminismo/s 32, diciembre 2018, pp. 181-203 
desplazados, empobrecidos, segregados o ignorados por las narrativas dominantes de la modernidad.

En este viaje adoptaremos una perspectiva materialista de corte spinoziano, articulado desde los estudios de la ciencia y la tecnología o los estudios de género. En este camino han sido clave igualmente los estudios postcoloniales y los caminos propuestos por los estudios feministas. Las aportaciones de autoras como Rosi Braidotti, María Puig de la Bellacasa, Donna Haraway o Karen Barad nos permiten imaginar unas prácticas del diseño capaces de dar cabida a una mayor y mejor relacionalidad de los seres humanos con las numerosas otras entidades con las que compartimos nuestra estancia en la Tierra y la coproducción de lo que llamamos mundo. Para ello, consideraciones relativas a la codependencia, la interdependencia, los cuidados o los afectos circularán a lo largo de todo el texto.

Queremos reconocer que nos sentimos próximos a algunas prácticas arquitectónicas ocurridas durante estos primeros años del siglo XXI, donde podemos localizar tanto esfuerzos metodológicos por construir relatos alternativos a los aportados por la racionalidad determinista que emerge de la presencia estructural de la negatividad, como sus repercusiones a la hora de redefinir las prácticas de diseño arquitectónico y su deseable consideración como prácticas políticas. Mencionaremos como especialmente inspiradores el trabajo del equipo Husos en el diseño de la vivienda unifamiliar Bathyard (2017) o el Prototipo bioclimático de edificio-jardín hospedero y nectarífero para mariposas de Cali y sus acciones para incentivar iniciativas no antropocéntricas de jardinería (2012); la propuesta sobre el papel de los cuerpos de la oficina Elii en la JF-Kit House (2012); o el proyecto colaborativo de Marina Fernández en su intervención Tejiendo la Calle (2013).

Sin embargo, en este trabajo nos pararemos brevemente en dos casos de diseño en los que el autor de este texto ha estado implicado y que aspiran a reflexionar a través de la práctica sobre la dimensión relacional de la arquitectura, sobre su condición de práctica de vecindad y sobre la pertinencia de considerarlas como éticas y estéticas de la reconexión.

Para hacer operativas las preguntas del comienzo nos concentraremos no tanto en los resultados obtenidos, sino sobre todo en su mismo interior, en el mismo momento en que las prácticas pueden estimular o alentar un llegar a ser de otra manera. Al menos nos interesará testear en ellas si existe

Feminismo/s 32, diciembre 2018, pp. 181-203 
la posibilidad de «enactar» las transformaciones por venir, auspiciadas por aquellas perspectivas que sitúan en el estatuto de lo humano la centralidad de sus debates. Esta búsqueda en el interior mismo de nuestras prácticas introduce un interrogante sobre las instituciones en torno a las cuales la arquitectura también se coproduce y socializa. Creemos que tanto la crítica arquitectónica como las escuelas de arquitectura han asumido en ocasiones una invisibilidad acrítica sobre su responsabilidad en la dimensión fundante de las distintas prácticas a través de las cuales la arquitectura acontece. Esta invisibilidad hace tiempo que está siendo cuestionada y este trabajo quiere contribuir a un deseable desplazamiento de la centralidad de los debates arquitectónicos desde los objetos mismos que produce hacia las éticas y las políticas desde los cuales se producen.

El objetivo final sería mejorar la comprensión de cómo sucede la arquitectura en nuestros entornos próximos, para poder redistribuir roles y responsabilidades entre todos los agentes que participan en el sostenimiento de este ámbito del saber, tan necesario o más que en los albores de la modernidad, cuando se fijaron muchos de los paradigmas de acción del arquitecto moderno. Entendemos que, si bien podemos estar de acuerdo en reconocer un proyecto de colonización inherente a los albores de Modernidad, en estos momentos, nos pensamos más próximos a un proyecto de emancipación colectiva que cuestiona el reconocimiento de lo humano como único estatuto posible afectado por la arquitectura. Algunos lo llamamos «proyecto de emancipación», otros «imperativos ecológicos», mientras que los más pragmáticos reconocerían en estos intereses un esfuerzo por comprender el futuro de la arquitectura en el marco de la precariedad económica y laboral del presente.

\section{LA PREGUNTA POR LA ALTERIDAD}

Las producciones arquitectónicas aparecen hoy en día en occidente lastradas por un cierto sentimiento de culpa por sus vínculos con el catastrófico estado del planeta. La relación entre producción de ciudad material e incremento de la emisión de los gases de efecto invernadero es innegable y, a menudo, la sostenibilidad como propuesta ha asignado a la arquitectura la ardua labor de limitar tanto las emisiones de este tipo de gases como el consumo de recursos energéticos y materiales. Aparentemente, para mejorar esta negatividad, la

Feminismo/s 32, diciembre 2018, pp. 181-203 
arquitectura tendría que mejorar sus prestaciones ambientales a través de un desarrollo tecnológico capaz de renovar nuestros pactos con la naturaleza sin alterar los repartos de poder inherentes a dichos pactos.

Sin embargo, ya desde la temprana aparición de la propuesta sostenible en el Informe Bruntland (1987), numerosas voces como la de Michel Serres en El contrato natural o la de Félix Guattari en Las tres ecologías la han problematizado por excesivamente antropocéntrica y, por tanto, preocupada casi en exclusividad por la gran familia humana. A juicio del último, la sostenibilidad, al menos en su definición originaria, estaría insistiendo en considerar a los «otros» no-humanos solo en relación con aquellos que aparecemos en primer plano, descuidando el papel que las interacciones y codependencias juegan en la producción del mundo. Con el paso de los años, este descuido ha magnificado en algunos sectores el papel que las tecnologías pueden jugar en un futuro a medio plazo en el ámbito de la arquitectura, mientras que otros estudios estarían cuestionando que las aportaciones de los avances tecnológicos en la reducción de los consumos consigan por sí mismas revertir el efecto negativo de las acciones humanas sobre la vida en el planeta. Pero fundamentalmente queda la pregunta sobre los no incluidos en las economías occidentales o sobre el estatus ético con que aparecen. De hecho, la tecnología no es abstracta y aparece articulada en el diseño a través de ideologías y economías con sus propios proyectos políticos, dejando de manera habitual fuera de juego a aquellos que más sufren los embates del cambio climático.

Este cuestionamiento de la sostenibilidad en favor de una mayor concentración en la dimensión relacional de la arquitectura como práctica nos remite a la ecología política y problematiza algunos rasgos inherentes a la Modernidad. Los modos de relacionarse implícitos en el proyecto arquitectónico se habrían basado en aspectos falsamente estructurales como la diferencia, el valor o la eficacia. La preservación del valor o su reproducción han formado parte, de hecho, de los grandes argumentos de la historia de la restauración arquitectónica. Preservar la memoria heroica inscrita en nuestros monumentos, dar testimonio de nuestro pasado, nos podía permitir, por ejemplo, hacer visibles con claridad la flecha del tiempo y la capacidad de la razón humana para avanzar hacia adelante. Tener cerca y en un mismo espectro de lo visible el coliseo de Roma y la torre Eiffel nos permite medir los éxitos de la razón humana de manera indiscutible. También nos habría

Feminismo/s 32, diciembre 2018, pp. 181-203 
permitido establecer diferencias con los otros, con aquellos que no han llegado a tiempo. De hecho, estos modos de relacionarse en torno a la producción de valor se apoyan sobre la activación de pares de opuestos como mal/ bien, útil/inútil, amigo/enemigo, bello/feo, vencedor/vencido, etc. Es esta polarización interesada la que serviría para asignar valor a unas en detrimento de otras. Intensificando por un lado las diferencias, haciéndolas visibles por otro, y finalmente perpetuando su condición de negatividad, como veremos más adelante. Uno de los tropos más exitosos sobre los que se asientan las prácticas arquitectónicas arranca precisamente de una de estas dicotomías: la ecuación problema-solución. El arquitecto moderno, desde sus herramientas y capacidades, era capaz de aislar un problema de un entorno real y superar su negatividad por medio de una solución arquitectónica. Así, Izaskun Chinchilla plantea en su tesis doctoral la siguiente pregunta: «¿Por qué es importante para la ecología que los arquitectos duden de que la arquitectura resuelve problemas?» (19). Para ella, la estructura tradicional de resolución de problemas implica dos enormes riesgos: simplificar las cuestiones medioambientales y desactivar la sensación de urgencia y corresponsabilidad.

En el ámbito del diseño, esta pregunta sobre el valor y las relacionalidades que incorpora es relevante, por cuanto el diseño tiene la capacidad de ensamblar materialidades, sensibilidades y ámbitos de relación muy heterogéneos. En consecuencia, es también capaz de promover redistribuciones de poder y visibilidad, de organizar nuestros cuerpos de otras maneras y de recomponer el mundo sensible. Estos procesos de transformación política a menudo son lentos y diferidos en el tiempo, pero es indudable que suceden y están siendo cada vez más estudiados en la búsqueda de aproximaciones más sensibles con los problemas del planeta. En esta línea, la necesidad de transformaciones estructurales que afecten en profundidad a nuestras maneras de estar juntos, o el cuestionamiento de los límites impuestos por el estatuto de lo humano, son tareas pendientes que atraviesan cualquier consideración sobre el futuro y los alcances políticos de las prácticas arquitectónicas.

Para escapar de las exigencias eficacistas de la modernidad y de la trampa del valor como paradigma de lo relevante, numerosos autores y, en especial, autoras, se han dirigido desde sensibilidades próximas al feminismo hacia aquellas producciones humanas que han crecido y desarrollado al margen del valor económico y de las luchas por preservar y reproducir el valor. El ámbito

Feminismo/s 32, diciembre 2018, pp. 181-203 
de los cuidados, por ejemplo, está siendo objeto de intenso estudio solo desde épocas muy recientes, pero está ya aportando perspectivas ilusionantes sobre cómo relacionarnos con la alteridad de manera más justa, sin apoyarse en las lecturas reduccionistas ofrecidas por las polaridades excluyentes. Para autoras como Donna Haraway, es necesario superar todo tipo de pensamiento que se asiente sobre el paradigma de las diferencias ontológicas entre las especies, entre los unos y los otros (Haraway 1-9). Su propuesta pasa por ser capaces de generar conexiones inimaginables con los otros como una práctica para aprender a vivir y morir bien. Para ello sería necesario huir de la tentación de referirnos a un futuro mejor pacificado y asumir de raíz lo que supone instalarnos en la continuidad de los problemas del presente. Para esta titánica tarea, el arte es un lugar privilegiado para imaginar otros futuros donde las interacciones puedan superar de manera creativa las diferencias autoimpuestas por la modernidad. Nosotros queremos incluir la arquitectura como una de estas prácticas privilegiadas desde las cuales pensarnos juntos de otra manera. Otras autoras, como Karen Barad, insisten en la superación de todas aquellas visiones que asignan el estatus de lo real a las entidades individuales, situando en lo que acontece en el seno de las prácticas toda la centralidad de lo que somos (Barad 818-824). Para Barad, las prácticas aparecen siempre encarnadas y situadas, no son productos exclusivos del pensamiento. Las prácticas lidian con nuestras inmanencias y contingencias, tienen nuestra medida, asumen nuestra lesa humanidad. Llegan hasta donde nosotros y nosotras llegamos. A su vez, se hacen presentes articuladas en numerosas políticas y pactos que se negocian en el tiempo y a la luz de las necesidades de cada presente. Y es ahí, añadimos, donde las prácticas arquitectónicas se juegan su futuro. En la misma línea queremos situar el trabajo de Isabel Stengers, para quien pensar en nuevas composiciones que superen la condición individual es imprescindible si queremos resistir con éxito a la barbarie del presente (Stengers, Introductory notes on an ecology of practices 183-196). Un presente marcado por la intrusión de Gaia y por los excesos del capitalismo. Para Stengers no son nuestros objetos los que se sienten amenazados, son nuestras prácticas las que están en peligro, aquellos lugares de acción donde realmente llegamos a ser. No olvidemos que frente a la centralidad de la visibilidad que proponen los objetos, los estudios de género a menudo han utilizado la estrategia de escapar del régimen de lo visible, de huir de los dominios de lo

Feminismo/s 32, diciembre 2018, pp. 181-203 
racional, hacia aquello que hacemos cuando estamos juntos. Las prácticas, en cambio, parecen ser un reducto de invisibilidad. Las prácticas acontecen y desacontecen. Sus producciones son instantáneas. Sus resultados operan a medio y largo plazo. ¿Cuánto debemos de lo que somos hoy a lo que hicimos hace muchos y siempre con otros, con otras? Las prácticas disparan un capital político y un aparataje ético diferente que a menudo ha sido inobservado por la crítica arquitectónica. ¿Cómo operamos en nuestros lugares de acción? ¿Qué ocurre con las cajas negras del diseño, de la arquitectura?

En su conjunto, este tipo de estudios nos confrontan con la pregunta sobre la alteridad, esos otros que con frecuencia han sido excluidos de los relatos dominantes de la modernidad, aportando tanto perspectivas más comprometidas con el presente como herramientas concretas de acción desde nuestros respectivos ámbitos de estudio. Pero no se trata solo de un asunto de justicia social, sino de localizar en la relación con la alteridad la condición fundante de lo que llegamos a ser y de lo nuevo por venir. Y es en esta apertura al futuro donde la moral universal kantiana que emerge del sujeto autocentrado se ve más cuestionada por la necesidad de unas éticas más atentas con la alteridad situada.

Para Rosi Braidotti, tres son las líneas de trabajo que nos permitirían una aproximación más justa a nuestra relación con los otros (Por una política afirmativa 170-192). Las tres con grandes implicaciones por desarrollar para la arquitectura como práctica material. En primer lugar, Braidotti propone insistir en una ética radical de la transformación en oposición a los protocolos morales del universalismo kantiano. ¿Cómo pensar, desde esta óptica, en una arquitectura que no se resuelve en el estado ideal del objeto acabado, sino que pasa a ser pensada como una entidad que cohabita con otra, que propone transformaciones en los modos de estar entre los otros? En segundo lugar, propone desplazar la atención de la conciencia unitaria, guiada por la racionalidad, a la ontología del proceso, es decir, a una visión de la subjetividad movida por afectos y relaciones. Este aspecto estaría cuestionando la autonomía de la arquitectura como práctica desencarnada y abstracta, tan en la línea del pensamiento heteropatriarcal. Asuntos como el espacio o la luz, tan anclados en esencialismos inalcanzables y tan protagonistas del discurso moderno, se ven ahora rodeados de contingencias como la carnalidad de los cuerpos, la urgencia de los deseos, o lo inaprensible de la voluntad individual.

Feminismo/s 32, diciembre 2018, pp. 181-203 
En tercer lugar, para Braidotti sería preciso desvincular la constitución del sujeto de la lógica de la negación para devolver la subjetividad a la alteridad afirmativa. Esta aspiración de un proyecto afirmativo que supere las limitaciones del pensamiento dicotómico es quizás su propuesta más ambiciosa y sobre la que se asienta una gran parte de su proyecto intelectual (The New Activism 264-271). A su vez, constituye a nuestro juicio el punto de partida de una reflexión crítica capaz de alimentar propuestas de relacionalidades alternativas más inclusivas y que se manifiesten como capaces de lidiar con los problemas del presente, afectando con claridad al ámbito del diseño. Su propuesta afirmativa cuestiona el paradigma de las diferencias ontológicas sobre las que se asienta la Modernidad, las cuales incorporan una negatividad y resentimiento insuperables. Si el bien aparece como respuesta al mal, la negatividad del mal estará siempre presente en la articulación del bien, por intenso que éste sea. A su juicio, deberíamos estar más atentos no tanto a las categorías del pensamiento racional, sino a las condiciones de posibilidad que se abren en el continuo estar junto a otros. En este sentido, sería una ética sostenible y no la moral universal la que nos permitirá limitar los riesgos y perseguir, al mismo tiempo, un proyecto original de transformación, ya que para pensar los problemas de un presente inabarcable necesitamos perspectivas orientadas hacia el futuro, que no renieguen de los traumas del pasado, sino que los transformen en posibilidades para el presente. No el paraíso futuro, sino un «aquí y ahora» situado y más sostenible. La tarea de las pensadoras y pensadores críticos del poder sería entonces valorar las condiciones favorables para el cambio social, en contraste con el acento puesto en los factores inmodificables.

En nuestro ámbito, esta cuestión nos lleva a preguntarnos ¿Qué tipo de prácticas pueden ayudarnos a superar esta negatividad implícita en el proyecto moderno? ¿Qué supone esta superación? ¿Cuáles son las prácticas arquitectónicas más acordes con los nuevos tiempos? ¿Qué significa hoy en día hablar de prácticas éticas frente a prácticas poco éticas? Para avanzar en estas preguntas, en el siguiente epígrafe visitaremos un episodio donde los modos de estar juntos y de conocer propuestos por la Modernidad fueron puestos a prueba a través de la aparición de asuntos como la empatía o los afectos, abriendo caminos insospechados que podemos reconocer hoy en algunas de las prácticas arquitectónicas que más nos interesan.

Feminismo/s 32, diciembre 2018, pp. 181-203 


\section{EL EXTRAÑO CASO DE LAS PRIMATÓLOGAS}

A lo largo del siglo XX ha habido episodios donde los modos de conocer a los que hemos aludido han sido cuestionados por modos alternativos que implicaban la aparición de otro conjunto de normas de uso e interpretación. Sobre todo, proponían otros modos de relacionarse con la alteridad. Estos otros modos especulaban con la posibilidad de reconocer como sujetos éticos y, por tanto, sujetos de derecho, a entidades que las éticas tradicionales habrían dejado fuera de sus preocupaciones. Animales no humanos, parques naturales, minorías humanas segregadas, racializadas, feminizadas o naturalizadas, han sido así progresivamente incluidas en otros sistemas éticos que ambicionaban reconocer la diversidad de muy distintas formas de existir y la posibilidad de operar sin una centralidad estable. Podríamos pensar que justificaban la pertinencia de estos reconocimientos en aras de una mejor manera de estar juntos en el planeta. En este trabajo queremos hacer presente lo que llamaremos el extraño caso de las primatólogas, descrito desde los entornos académicos por la pensadora ecofeminista Alicia Puleo o la antropóloga Salmacis Ávila. Un episodio en la historia de la ciencia reciente que supuso un reto a las limitaciones del tipo de conocimiento que soportaba la Modernidad como proyecto y que afectaba incluso al estatuto de lo natural y de lo humano.

En los años 60, el ilustre paleontólogo Louis Leakey estaba preocupado porque con los protocolos estrictos del método científico el conocimiento de los primates estaba entrando en vía muerta. El método científico se arrogaba en exclusividad para la razón humana la autoridad para «torturar a la naturaleza para que nos muestre sus secretos», como rezaba la premisa de Francis Bacon. En esta relación entre pares excluyentes -humanos y no-humanos-, cuestiones como los afectos o la empatía no gozaban de estatus privilegiado ni relevancia, lo cual resultaba especialmente problemático a la hora de abordar el estudio de grandes primates. Es cierto que podemos coger un vegetal y trocearlo infinitamente hasta deducir ciertos principios generales sobre su comportamiento, pero incluso hoy en día el estudio de la vida vegetal está cuestionando cualquier simplificación mecanicista sobre el funcionamiento de los organismos vivos, como nos muestra el trabajo de investigadoras como Natasha Myers. La especial manera con la que lo real se ensambla parece

Feminismo/s 32, diciembre 2018, pp. 181-203 
demandar estudios que vinculen afectos y comportamiento para una mejor comprensión de sus modos de estar juntos.

En el caso que nos ocupa, la necesidad de otros medios exploratorios era obvia, pero de difícil realización. En ese contexto, Leakey envió sucesivamente a tres mujeres carentes de formación expertizada en el ámbito de los grandes simios, pero con habilidades contrastadas en el ámbito de la educación o la mediación social. Además, se trataba de mujeres que ya habrían manifestado una empatía e interés personal por los grandes primates. Hablamos de Biruté Galdikas, Jane Goodall y Diane Fossey. Cada una de ellas y en momentos diferentes, partieron a estudiar a los grandes simios en distintos lugares del planeta. Sin la adecuada vigilancia de las instituciones científicas, desarrollaron maneras particulares de aproximación para relacionarse con esos otros que tan reluctantes se habrían mostrado hacia las torturas propuestas por el método científico. A través del uso de los afectos y los cuidados, estas extrañas primatólogas impulsaron acciones de empatía y reconocimiento con sus objetos-sujetos de estudio que cuestionaban la diferencia ontológica entre humanos y no humanos. Su trabajo produjo un retorno cognitivo imprevisto en aquellos momentos y supuso un modelo alternativo de conocer que aún hoy genera controversias. Demostraron, por ejemplo, que las premisas sobre las que se asentaban las diferencias propuestas por el Homo Faber no eran ciertas y que tal diferenciación se apoyaba exclusivamente en la incapacidad del método para acceder con plenitud a las producciones de los primates.

Mediante recursos aparentemente inocentes como asignarles nombres a los primates en lugar de números codificados hasta esfuerzos de mímesis, integración, asunción de roles, etc., sus investigaciones fueron dando sus
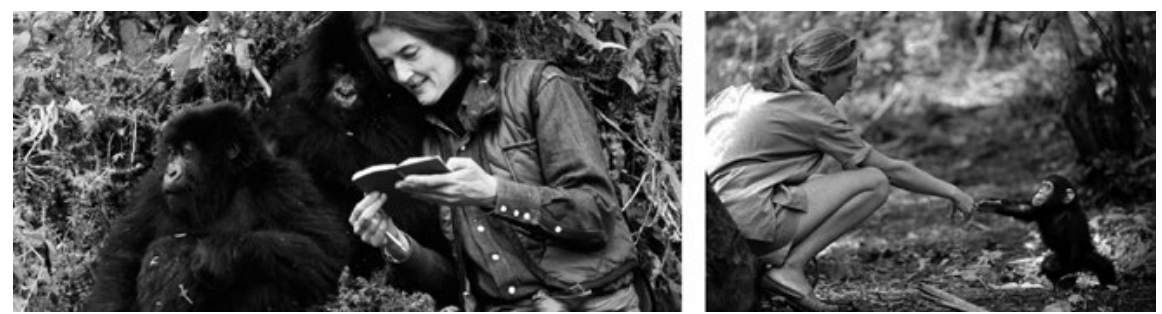

Imagen 1. Dian Fossey y Jane Goodall durante sus investigaciones con simios.

Feminismo/s 32, diciembre 2018, pp. 181-203 
frutos en la medida que los simios «también» fueron reconociendo en ellas sujetos dignos de atención y reconocimiento. Algunas de las imágenes que nos han llegado de ellas, nos muestran actitudes compartidas donde la jerarquía habitual entre observador y observado han perdido sus respectivos lugares de enunciación en favor de acciones colaborativas que producen resultados en muy diversas direcciones. Este tipo de implicaciones desde el cuerpo propio, experimentando no solo con los objetos de estudio sino sobre todo con las propias maneras de conocer, exige un esfuerzo de redimensionamiento por parte de todos los agentes que participan en los procesos cognitivos, lo cual demanda posiciones éticas y compromisos políticos poco observados por la historiografía de la ciencia. Además, pone a prueba a todas aquellas instituciones encargadas de la producción, trasmisión y articulación del conocimiento, como sería el caso de la Universidad.

Este tipo de actitudes aspiraba a superar la dialéctica hegeliana del tú y del yo en favor de un nosotros en permanente redescripción, evaluación y chequeo. Un tipo de relación dinámica que evoluciona en el tiempo y que también altera el devenir de los cuerpos implicados en el proceso. Es un tipo de experimentación en que científicos y primates dejan de ser categorías excluyentes en favor de unos y otras juntas en un proceso de llegar a ser sin límites ni fines preconcebidos. En el caso de Diane Fossey, más conocida por recogerse su vida en la película Gorilas en la niebla, esta implicación se transformó en un activismo político en defensa de los grandes simios cada vez mayor que derivó en su asesinato en el año 1985, probablemente a manos de cazadores furtivos contrarios a su deriva hacia la defensa de estos animales.

El camino iniciado por el episodio de las primatólogas desde los años 60 ilustra algunas cuestiones importantes para las prácticas arquitectónicas. No olvidemos que tanto la ciencia como la arquitectura son dos de las más exitosas y disciplinadas disciplinas puestas a punto por la Modernidad. En el caso de la arquitectura, su eficacia fue tal que en apenas unos años, la colonización del mundo por el proyecto moderno sucedido en la primera mitad del siglo XX impuso a las ciudades una fisionomía unitaria que puso imagen al conjunto del proyecto moderno. Todo sucedió, además, a una velocidad inusitada en la historia de la humanidad.

A pesar de que también a lo largo del siglo XX se pueden constatar disidencias respecto de los cánones promovidos por la Modernidad, lo cierto es

Feminismo/s 32, diciembre 2018, pp. 181-203 
que tanto las urgencias del presente como las herramientas teóricas aportadas por los estudios feministas y postcoloniales, permiten pensar en un cierto cambio de paradigma a la hora de imaginar cómo las prácticas arquitectónicas pueden reconsiderar la condición ética de otros sujetos menos hegemónicos, aprendiendo a relacionarse con ellos de manera más simétrica y redistributiva. Proyectos como los propuestos al principio de este texto han conseguido llamar la atención de la crítica por activar el proyecto arquitectónico en torno a sujetos carentes de valor para las economías capitalistas, proponiendo en cambio los cuidados y los afectos como dinámicas propias a impulsar y recoger en el proyecto.

Y es en esta línea que en este trabajo propondremos dos pequeños estudios de casos que se quieren situar precisamente en esta línea de imaginar las prácticas arquitectónicas como prácticas de reconexión, en lugar de prácticas de segregación. Ambos casos aspiran a entenderse como prácticas de resistencia a los excesos de la modernidad y del neoliberalismo, aunque el objetivo de este trabajo no sea explicar estos casos en su totalidad. En ambos casos el autor de este trabajo ha participado como coordinador y en ellos se ha intentado escapar a la centralidad que suponen la preservación o reproducción del valor económico en los proyectos donde el patrimonio es convocado. En ambos trabajos, además, el papel de las tecnologías ha sido muy relevante, por cuanto han sido precisamente ellas las depositarias principales de esta descentralización. Por su condición material y su capacidad de aparecer y desaparecer del ámbito de lo visible, los procesos de diseño han dirigido su interés prioritario a esta parte del proyecto.

\section{PAJARERAS ALTERNATIVAS}

Examinemos ahora el objeto de la imagen que aparece a continuación. Se trata de una pajarera, un objeto que contiene vida animada por el color, el movimiento y el sonido. Le llamamos pajarera, pero también puede considerarse un dispositivo para alojar videoproyectores en un Centro de Videoarte (EDOM) que funciona desde 2014 en dos casas abandonadas de un pueblo del interior mediterráneo. Por tanto, también un objeto del cual emana movimiento, color y sonido, además de luz. En este objeto, otros podrían adivinar un conjunto de finas planchas de metacrilato color flúor o malva decoradas

Feminismo/s 32, diciembre 2018, pp. 181-203 

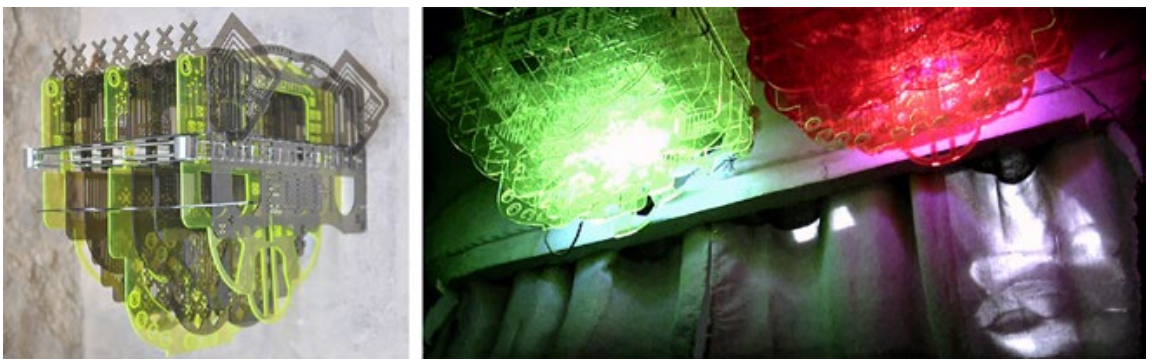

Imagen 2. La pajarera de EDOM.

con geometrías provenientes de las antiguas baldosas hidráulicas que decoraban muchas casas populares mediterráneas. Últimamente, al transportar la pajarera a un congreso de antropología y diseño, fueron también consideradas como peligrosas armas potenciales en el aeropuerto de Alicante y como una posible obra de arte robada en el aeropuerto de Gatwick, Londres. En dicho congreso, la pajarera, en su radical materialidad, demostró ser un objeto capaz de «enactar» la arquitectura allí por donde va. Allí donde es montada y presentada.

Esta pajarera fue diseñada en colaboración con Rosana Galián y Paula Vilaplana como parte de una familia de objetos que debían traducir a las necesidades de un centro de videoarte algunos de los objetos y referencias que pueblan los espacios domésticos de nuestros entornos. Este objeto fue codiseñado y ensamblado por ellas, mientras que otros, como los textiles, fueron cosidos por los colectivos de mujeres de Blanca, el pueblo del que estamos hablando. Estas últimas necesitaban desde hacía tiempo una máquina de coser, pero la concejalía de servicios sociales no disponía de presupuesto. Para EDOM la adquisición de una máquina de coser fue un gasto pequeño y constituyó la base del trato. A cambio de la máquina, las mujeres coserían todo aquello que el centro pudiera necesitar. Por otro lado, las mujeres esparteras de una de las escasas fábricas de esparto que aún resisten el embate de las economías globalizadas aplicaron sus tecnologías a asientos y tapices, a los que se superpusieron igualmente las geometrías del pavimento existente. Y así con todo tipo de objetos, tecnologías y domesticidades. En su conjunto el diseño de este Centro de Videoarte supone un esfuerzo por reinsertar los procesos 

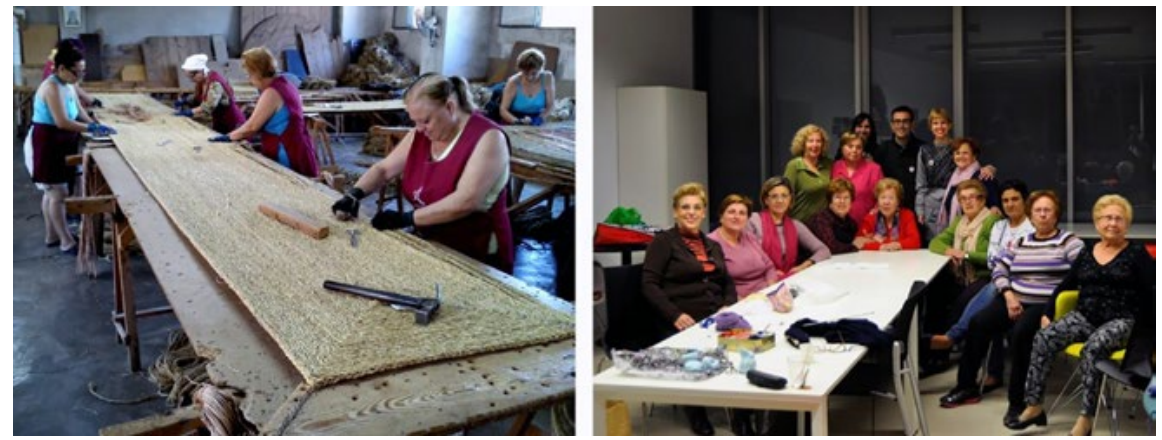

Imagen 3. Esparteras de Blanca trabajando y el grupo de la asociación de mujeres.

de diseño contemporáneo en economías, sensibilidades y tecnologías locales, encontrando en esos lugares de enunciación un potencial creativo y activista.

La casa fue habitada durante muchos años por Pepe, un hombre que salía poco y siempre embozado. Siempre de noche. Su casa era conocida como la casa del Conde Drácula. Pepe iba al cementerio embozado y de noche. La mentalidad del pueblo solo podía recurrir a ciertos imaginarios televisivos escabrosos para explicar sus salidas nocturnas. La mentalidad postfranquista del pueblo no les permitía imaginar que Pepe tenía prácticas afectivas y sexuales alternativas y que recurría a la trasera del cementerio para dar salida a sus impulsos. La vida de Pepe, ultracatólico y gay, fue cada vez más tortuosa. Sus jaquecas continuas le llevaron a clausurar muchas de las ventanas de la casa, cuyo interior pasó así a ser objeto de estos confusos imaginarios. Al acceder a la casa y pasar allí unas primeras semanas, nos encontramos con que vecinos y vecinas se acercaban con curiosidad para saber cómo era aquel interior, qué rastros y huellas quedaban del pasado de Pepe. Para nosotros, arquitectos modernos, allí no había nada de valor. Lo mejor hubiera sido demolerlo todo, barrer aquellos recuerdos intangibles. No olvidemos que las herramientas de la arquitectura tienen grandes problemas para acoplarse a situaciones de ausencia de valor, especialmente cuando el diseño no está orientado a la preservación de este o a la reinstalación de lo material en los flujos económicos. Afortunadamente, no sucedió así. Este proyecto fue para las personas involucradas en su diseño una experiencia de desaprendizaje,

Feminismo/s 32, diciembre 2018, pp. 181-203 
de descentramiento respecto de los mandatos de la modernidad. Durante el proceso, la teoría aspiraba a encarnarse en un proceso material.

La propuesta consistió en «despegar» las acciones arquitectónicas de las superficies de las paredes e implosionarlas en unos objetos que mediarían entre los imaginarios y las materialidades del pasado y del presente. Queríamos preservar de algún modo la memoria de lo acontecido, hacer presente las sensibilidades del ensamblaje Pepe-casa y a su vez imaginar unas intervenciones de videoarte en esos contextos. De esta manera, evitaríamos también el aterrizaje del videoarte como un alien en un conjunto de comunidades poco aficionadas a estos asuntos tan «modernos». Son los objetos los que aglutinan y ensamblan ambas sensibilidades. Y, fundamentalmente, las tecnologías, despojadas aquí de su cometido garantista habitual. Lejos de las pretensiones de cumplir con el código técnico de la edificación, las tecnologías aquí son consideradas como estrategias de seducción y traducción.

Los diseños de este centro de videoarte sirven también para pasar de una historia de oscuridad, una historia en la que la ausencia de luz constituye la estructura política del discurso, a una historia sobre la aparición de la luz y el color, o cómo la ausencia de este no significa necesariamente situaciones de opresión y segregación. El arte como disciplina ha resultado fundamental en este tránsito.
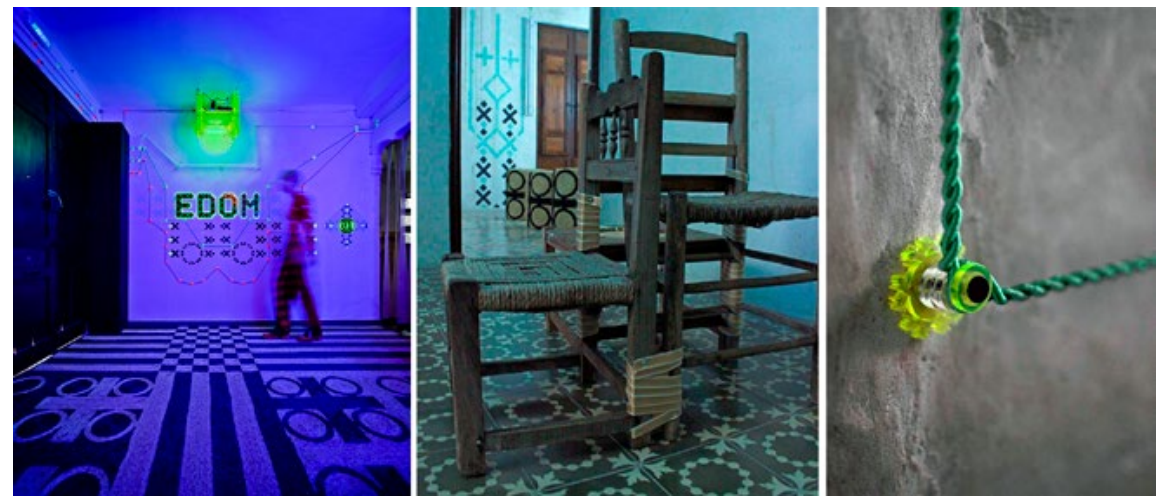

Imagen 4. Estrategias de seducción mediante tecnologías afectivas en EDOM.

Feminismo/s 32, diciembre 2018, pp. 181-203 


\section{CUIDAR LA MEMORIA, ATENDER AL PRESENTE}

Pasemos a un segundo caso de estudio. En una céntrica plaza de otra ciudad mediterránea coexisten pacíficamente tres edificios institucionales. Por un lado, la iglesia católica barroca que da nombre a la plaza y también al barrio. Se trata, además, de una de las estampas que más ha ayudado a fijar la identidad popular de esta ciudad. Su valor histórico va ligado a la tradición y al papel articulador de la vida social que en esta ciudad ha tenido la doctrina cristiana. Tanto el valor patrimonial como el inmaterial quedan fijados en la catalogación de la iglesia como Bien de Interés Cultural por parte de su comunidad autónoma. Por otro lado, el Museo de la muralla árabe, una carcasa de protección de una presencia aún más antigua que la iglesia y que sucumbió al poder político y militar que acompañaba en aquellos días al poder religioso. Este museo, además, va acompañado de todo un aparataje interpretativo que permite ubicar con precisión en el relato de la historia el papel que jugó este ensamblaje material, así como su subordinación respecto de la cultura cristiana. Esta interpretación, tan propia de la modernidad, delegaba en los expertos la interpretación de la historia dentro del relato exitoso del progreso ilimitado de nuestras sociedades occidentales. Sus textos parecen decir: «ahora somos esto porque en su momento fuimos lo otro». También parecen afirmar que somos más ciertos porque en su momento les derrotamos. Su valor patrimonial fija en la condición histórica, en la superposición de las culturas y en la preservación de estas capas, uno de los cánones para la construcción de nuestra pertenencia identitaria. El museo tiene una fuerte presencia visual, su diseño fue realizado por arquitectos de prestigio y su envolvente de madera se aleja adecuadamente de la presencia pétrea de la iglesia para aclarar sus distintos orígenes y su distinto papel en la producción de la memoria histórica.

Al lado de estas dos construcciones significativas, en la planta baja de un edificio de vivienda de los años $60 \mathrm{del}$ pasado siglo, se acomoda un centro de mayores de barrio. Su presencia es discreta, apenas señalada por una placa convencional. En el marco de correspondencia moderna entre valor y visibilidad, con esta presencia anónima queda claro que nuestros mayores no poseen gran valor como colectivo, quizás sí para cada una de sus familias. 


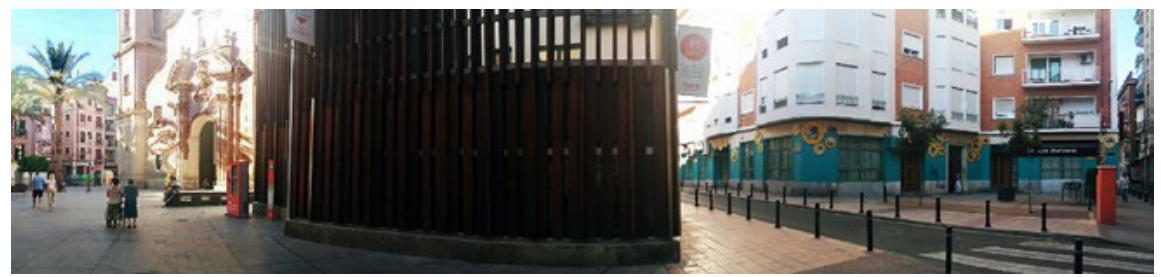

Imagen 5. Iglesia, Museo de la muralla árabe y Centro de mayores de Santa Eulalia.

Su presencia no demanda tipologías edificatorias precisas ni señaladas. Están allí porque en algún lugar tienen que estar.

En el marco de la intervención municipal ADN Urbano de Murcia, todo este barrio de Santa Eulalia fue objeto en 2017 de pequeñas intervenciones por parte de un equipo interdisciplinar que se propuso como objetivo incorporar ciertas realidades olvidadas a las acciones de diseño urbano. Se procedió así a reforzar la presencia histórica de la comunidad judía o a implementar pequeños usos comunitarios vinculados al disfrute vecinal. En los informes preliminares se detectó que algunas instituciones públicas del barrio ofrecían gran capital simbólico, pero no habían sido objeto de acciones de diseño significativas. En este contexto, este centro de mayores parecía, desde su condición periférica, un buen lugar para pensar el papel que los mayores juegan en nuestra sociedad. Queríamos involucrarlos en una estrategia de diseño donde el valor de uso fuera reemplazado por una acción que les comprometiera afectivamente y les implicara también a ellos en la construcción de la ciudad visible y material.

La propuesta desarrollada en colaboración con las arquitectas María José Marcos y Rosana Galián consistió en la elaboración de unas mesas de trabajo con los mayores del centro en las que se les solicitaba fotografías antiguas que documentasen la presencia de lo doméstico y lo afectivo en el espacio público. Con esta petición se quería apelar a la construcción colectiva de este tipo de espacios. Aparecieron así numerosas fotografías de fiestas populares, bodas, cumpleaños, etc., que daban cuenta de la enorme producción de afectos positivos y diversidad que componen los tejidos sociales, así como de la importancia de los eventos en el espacio público.

La intervención continuó con la transposición de estas imágenes a señales de tráfico recicladas, pintadas con códigos cromáticos provenientes de

Feminismo/s 32, diciembre 2018, pp. 181-203 

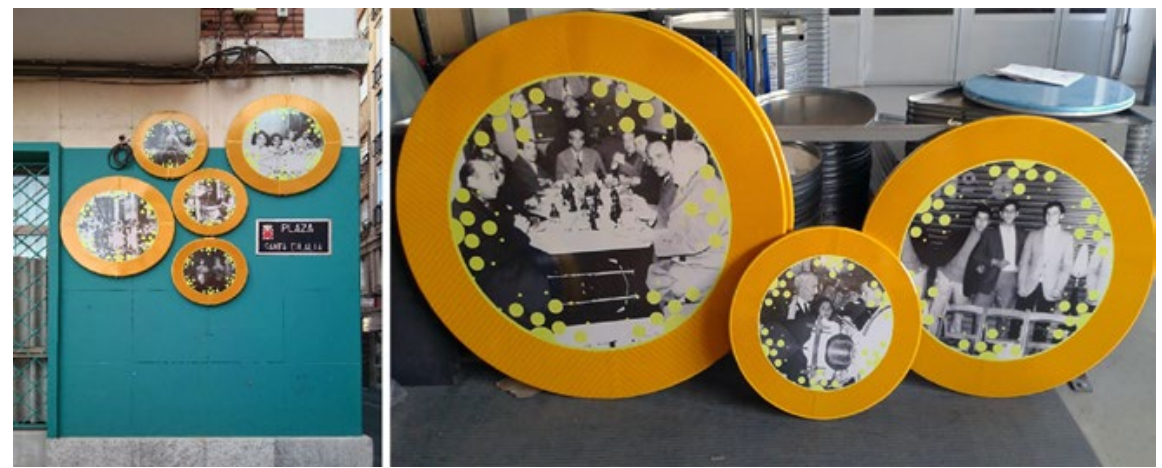

Imagen 6. Memorias materiales ensambladas en señales de tráfico.

la cultura contemporánea, y con su instalación en la fachada del centro. En su conjunto, la intervención parece querer hacer público otro tipo de valor alejado del valor patrimonial referido anteriormente, más próximo al valor de los afectos que se articulan en la vida social. La acción consistió, por tanto, en cuidar de este patrimonio inmaterial, de traducirlo a inscripciones materiales capaces de convivir con los otros dos grandes relatos de la plaza y especular sobre su dimensión productiva.

Desde el primer momento los mayores del centro se sintieron reconocidos en este tipo de prácticas, tan próximas a su cotidianeidad. Seleccionar y compartir fotografías de acontecimientos familiares no constituye una práctica expertizada. Menos aún puede considerarse una práctica de diseño profesional. Pero este fue precisamente el esfuerzo de esta intervención. Es un caso que reconsidera la dignidad de las historias dignas de ser contadas y de formar parte de las herencias materiales que la arquitectura produce en su práctica cotidiana. Cuidar de los mayores también significa atribuir un valor a lo único que tienen, su memoria, así como a su capacidad para interpretarla y seleccionarla.

Para acabar, es fácil imaginar las conversaciones que pudieron tener lugar en el proceso de diseño compartido. ¿Tan diferentes fueron las vidas de santos que ilustran la fachada de la iglesia de las suyas? ¿Tan especiales fueron las inscripciones de los árabes que vivieron hace varios siglos? ¿No formamos también parte, cada uno de nosotros y nosotras, de la historia? 


\section{EL DISEÑO ARQUITECTÓNICO COMO PRÁCTICA PARA LA RECONEXIÓN}

Los dos estudios de caso descritos ilustran parcialmente los esfuerzos del diseño por articular sus prácticas desde racionalidades alternativas capaces de incluir a algunos de «los otros», tanto humanos como no humanos. En ellos, nos hemos fijado no tanto en el resultado de las producciones materiales como en la capacidad fundante del interior de sus prácticas para reconectar asuntos y agentes que ahora nos parecen dignos de una mayor atención. Por medio de este tipo de desplazamientos, ensayamos la posibilidad de instituir desde dentro de la arquitectura entornos de posibilidad capaces de reconectar al flujo de lo social fragmentos de vida descartados por su ausencia de valor. Además de este tipo de incorporaciones, los casos narrados ensayan desplazamientos en las asignaciones simbólicas de las tecnologías o los materiales, para reubicarlos en contextos afectivos que operan a través de la seducción y el deseo. Más allá del convencimiento de que la arquitectura necesita de este tipo de actualizaciones, lo cierto es que las herramientas heredadas de la Modernidad, tan eficazmente consolidadas a lo largo del siglo XX, se ven puestas a prueba cuando sus criterios de juicio (claridad, orden, jerarquía, valor, eficacia funcional, estabilidad, continuidad, etc.) pierden su centralidad en favor de otro tipo de asuntos más sensibles con aquellos «otros» no tan tenidos en cuenta en los procesos habituales de diseño.

Ante la progresiva exigencia de hacer nuestras prácticas más inclusivas y relacionales, el diseño arquitectónico ya no se resigna a ser una mera herramienta para la ecuación problema-solución, si el coste es mantener inalterados los repartos de poder que «ocurren» en torno a la arquitectura. Nuestros conjuntos de prácticas no quieren ser tan obedientes con unos mandatos que se soportan en unos pactos no negociados, y prácticas como las reseñadas parecen demandar otro conjunto de criterios para fijar su pertinencia o deseabilidad. En algo así también consiste el ser ecológicos. Y en este camino los aportes del pensamiento feminista han explicitado de manera muy convincente algunos modos útiles para manifestarse disconforme con los mandatos pacificadores heredados.

En el caso del centro de mayores, no había ninguna necesidad de aspirar a mejorar la subjetividad de sus moradores, ni nadie nos pidió situar la memoria 
cotidiana de nuestros mayores en una posición simétrica respecto de santos, descubridores o libertadores. Tampoco la implicación de los colectivos de mujeres en un centro de videoarte o la traducción material del sufrimiento de su último morador garantizan una mejor exhibición de sus contenidos. Por lo tanto, estamos hablando de otra cosa. Hablamos de la voluntad de la arquitectura de seguir formando parte de las prácticas relevantes a través de las cuales se debaten los problemas pertinentes para cada momento particular. Y asuntos como la mejora de la capacidad relacional de las prácticas, la descentralización del objeto hacia una consideración más performativa de los procesos arquitectónicos, la explicitación de las éticas que se articulan en los distintos modos de hacer arquitectura o la posibilidad de modificar el estatuto de los «otros» por medio de las prácticas de diseño, parecen hoy en día asuntos dignos de ser explorados y debatidos en contextos preocupados por el futuro de nuestro planeta.

Aunque no ha sido objeto de este trabajo, conviene insistir en que, ante este renovado interés por la capacidad política de las prácticas, es necesario señalar las crecientes dificultades por soportar la arquitectura exclusivamente desde las éticas kantianas, que irradian desde la centralidad que propone un ser humano probablemente macho, blanco, heterosexual, productivo y sano, tan bien imaginado por Leonardo da Vinci en su hombre vitrubiano. En su lugar las éticas que nos proponen los ecosocialismos o los ecofeminismos, el pensamiento interespecie o las ecologías queer, nos serán más útiles para imaginar y legitimar el tipo de prácticas al que estamos dirigiendo nuestra atención. A partir de ellas, la discusión sobre lo que es o no una buena práctica ya no parece limitarse al cumplimiento de unos trámites administrativos o de unos estándares de calidad consensuados desde el objeto acabado. Por el contrario, la discusión se abre a través de la especulación hacia la deseabilidad, por ejemplo, de los efectos que produce la propia práctica sobre las distintas entidades que intervienen, o la detección de las redistribuciones de poder que proponen, o los modos de estar juntos que de hecho «enactan».

Algunas pensadoras feministas citadas a lo largo del texto como Haraway o Braidotti han señalado explícitamente el arte como uno de los lugares relevantes donde la Modernidad está siendo desafiada y donde otras sensibilidades están siendo ya representadas. Ya en los años 70 del pasado siglo las prácticas artísticas feministas manifestaron una gran capacidad para hacer

Feminismo/s 32, diciembre 2018, pp. 181-203 
frente a la dimensión política de su presente sin complejos ni condescendencia. Aspiraban ya entonces a debatir en los mismos términos que la teoría. En la actualidad, el carácter tan heterogéneo de los asuntos que nos importan remite de nuevo a la centralidad de las prácticas como lugares privilegiados para discutir la teoría. Lo que buscamos a través de esta indagación en las prácticas de diseño, en definitiva, es una manera diferente de construir mundo con los otros, oportunidades actualizadas para otra coexistencia. De ahí nuestro interés por este tipo de corrientes de pensamiento, útiles para la emancipación no solo de las mujeres respecto del heteropatriarcado, sino de cualquier disciplina, como la arquitectura, diseñada desde las prescripciones del proyecto moderno.

Los órganos formativos de la arquitectura, las universidades, se encuentran a su vez ante el desafío de repensar la constitución política de sus aulas. Porque ahora no parece ya el momento de usarlas para insistir en sancionar lo que está bien y lo que no, sino de pensarlas como lugares de apertura hacia aquello que está por venir. Como nos recuerda Braidotti, «la tarea de las pensadoras y pensadores críticos del poder es valorar las condiciones favorables para el cambio social, en contraste con el acento puesto en los factores inmodificables» (Por una política 176-177). Por tanto, también la universidad tiene la responsabilidad de debatir sobre las prácticas emergentes y disidentes con las hegemonías del momento para ensayar su pertinencia o deseabilidad, sus condiciones de posibilidad ante un futuro que necesita ser más ecológico.

En este sentido, el reto de la Universidad con respecto a este tipo de prácticas es ayudar a elaborar paralelamente unos criterios de juicio y unos estándares de calidad alternativos que puedan ser debatidos y negociados en su interior. Este proceso es lento, pero sumamente excitante. Exige pensar nuestras prácticas arquitectónicas al lado de las producciones teóricas más relevantes en los tiempos que corren. Pensarlas, al lado de o junto a. También a través de. Pero esto será objeto de posteriores ensayos.

\section{REFERENCIAS BIBLIOGRÁFICAS}

Ávila, Salmacis. «¿Mujer antes que científica? Notas para analizar el retrato de Dian Fossey (I, II y III)». Anthropologies (2016). 10 diciembre 2017. $<$ https://www.anthropologies.es/mujer-antes-que-cientifica-notas-para-analizar-el-retrato-de-dian-fossey-i/> <https://www.anthropologies.es/

Feminismo/s 32, diciembre 2018, pp. 181-203 
mujer-cientifica-notas-analizar-retrato-dian-fossey-ii/ $><$ https://www.anthropologies.es/mujer-cientifica-notas-analizar-retrato-dian-fossey-ii-2/>

Barad, Karen. «Posthumanist Performativity: Toward an Understanding of How Matter Comes to Matter». Signs 28 (3) (2003): 801-831.

Braidotti, Rosi. «The New Activism: A Plea for Affirmative Ethics». Art and Activism in the Age of Globalization. Lieven De Cauter, Ruben De Roo y Karel Vanhaesebrouk. Rotterdam: Nai, 2012.

- Lo posthumano. Barcelona: Gedisa, 2015.

- Por una política afirmativa. Itinerarios éticos. Barcelona: Gedisa, 2018.

Chinchilla, Izaskun. La estructura de la revolución ecológica. Diss. Universidad Politécnica de Madrid, 2015.

Guattari, Félix. Las tres ecologías. Valencia: Pre-textos, 2000.

Haraway, Donna J. Staying with the Trouble: Making Kin in the Chthulucene. Durham: Duke University Press, 2016.

Myers, Natasha. «Conversations on Plant Sensing: Notes from the Field». NatureCulture 3 (2015): 35-66.

- «Ungrid-able Ecologies: Decolonizing the Ecological Sensorium in a 10.000 year-old NaturalCultural Happening». Catalyst: Feminism, Theory Technoscience 3 (2) (2017): 1-24.

Puig de la Bellacasa, María. Matters of care. Speculative ethics in more than human worlds. Minneapolis; London: University of Minnesota Press, 2017.

Puleo, Alicia. «Mujeres por un mundo sostenible». Dossiers Feministes 14 (2010): 9-19.

Serres, Michel. El contrato natural. Valencia: Pre-Textos, 1991.

Stengers, Isabel. «Introductory notes on an ecology of practices». Cultural Studies Review 11 (1) (2005): 183-196.

- In Catastrophic Times. Resisting the Coming Barbarism. Open Humanities Press/Meson Press, 2015.

World Commission on Environment and Development (WCED). Our Common Future (Brundtland Report). United Nations, 1987. 